\title{
UTERINE BLOODFLOW VELOCITY WAVEFORMS BEFORE AND AFTER TRANSCERVICAL CHORIONIC VILLUS SAMPLING
}

\author{
T. E. COHEN-Overbeek, M. G. J. JAHOdA and J. W. WladimirofF \\ Department of Obstetrics and Gynaecology, Academic Hospital Rotterdam-Dijkzigt, \\ Rotterdam, The Netherlands
}

(Received 14 April 1989; in final form 28 June 1989)

\begin{abstract}
Flow velocity waveforms from the left and right uterine artery were studied relative to transcervical chorionic villus sampling (CVS) between 9 and 11 weeks of gestation in 12 uncomplicated pregnancies and 5 pregnancies resulting in second trimester fetal loss. There was no significant difference in mean pulsatility index (PI) as a measure of downstream impedance, between the left and right uterine artery. There were also no significant changes in PI relative to the CVS procedure both in uncomplicated pregnancies and in pregnancies ending in second trimester fetal loss.
\end{abstract}

Key Words: Uterine flow velocity waveform, Pulsatility index, Chorionic villus sampling.

\section{INTRODUCTION}

Chorionic villus sampling (CVS) is a widely applied technique to determine fetal genetic disease at an early stage of gestation (Sachs et al. 1988). CVS does not appear to alter the fetal growth potential (Williams et al. 1987) nor does it induce changes in the fetal behavioural state (Boogert et al. 1987). Based on serum AFP determinations, feto-maternal transfusion occurs in $50 \%$ of the patients as a result of the procedure (Warren et al. 1985). However, no correlation has been found between the number of catheter insertions, gestational age at sampling, or milligrams of tissue sampled and the occurrence of feto-maternal haemorrhage (Warren et al. 1985). The risk of spontaneous abortion after CVS has been evaluated by a number of investigators and is approximately $4 \%$ in experienced units (Jahoda et al. 1985; Brambati et al. 1987). There appears to be no relation between the extent of feto-maternal haemorrhage and the occurrence of spontaneous abortion (Ward et al. 1985).

Doppler ultrasound has been used to study the uterine circulation throughout gestation in order to determine alterations in the flow pattern which may predict an unfavourable outcome of pregnancy (Campbell et al. 1983; Stabile et al. 1988).

Correspondence address: T. E. Cohen-Overbeek, M.D., Academic Hospital Rotterdam-Dijkzigt, Department of Obstetrics and Gynecology, Erasmus University Rotterdam, Dr. Molewaterplein 40, 3015 GD Rotterdam, The Netherlands.
The question was addressed as to whether an intrauterine procedure in the first trimester of pregnancy causes a change in the flow pattern of the uterine arteries and if so, does it influence the subsequent course of pregnancy.

\section{PATIENTS AND METHODS}

Seventeen women at risk for fetal genetic disease consented to participate in the study after detailed information on the investigation was given.

The indications for chorionic villus sampling (CVS) were: advanced maternal age $(n=7)$, recurrence risk for trisomy $21(n=2)$, Klinefelter syndrome $(n=1)$, X-linked disease $(n=4)$, and metabolic disorders $(n=6)$. In three women there was a combination of advanced age ( $>36$ years) and one of the other above-mentioned indications for the CVS procedure.

Mean maternal age was 32.2 years (range 25-41) and the mean parity was 1.6 (range $0-4$ ). Mean pregnancy duration was 10.3 weeks (range 9-11).

CVS was performed by ultrasound-guided transcervical passage of a Portex or Angiomed catheter. The mean sample weight was $33.8 \mathrm{mg}$ (range 15-50). In four cases, two insertions were necessary to obtain the required amount of villi for fetal diagnosis.

Doppler recordings of the right and left uterine artery flow velocity waveform (FVW) were per- 
formed ten minutes prior to the CVS procedure and ten minutes and one hour following the CVS procedure. Doppler flow recordings were performed using a Kretz Combison 320-5 with a $4 \mathrm{MHz}$ duplex sector scanner. A $2.25 \mathrm{MHz}$ pulsed Doppler probe is attached off-set at an angle of $70^{\circ}$ and the Doppler beam is displayed on the real-time image. The spatial peak temporal average intensity of the instrument is less than $99 \mathrm{~mW} \mathrm{~cm}^{2}$ which indicates that the energy output is within the safety recommendations of the American Institute of Ultrasound in Medicine (AIUM 1977).

Patients were scanned in the semi-recumbent position with a full bladder. The transducer was orientated along the transverse axis of the uterus where in the lateral wall the entrance of the uterine artery into the uterus becomes visible. The sample gate of the Doppler beam was placed on the uterine artery and Doppler signals were displayed on the screen. The pulsatility index (PI) was calculated manually with a light-pen system. The PI is described as the peak systolic frequency minus the end-diastolic frequency divided by the mean of the maximum frequency outline and is an indication of the state of the peripheral vascular resistance (Gosling and King 1975). The average of three FVWs per vessel was used.

The influence of CVS on uterine bloodflow was analysed by changes in PI of the left and right uterine artery separately and changes in mean PI of both the right and the left uterine artery together. The maternal heart rate was calculated from the mean transit time on screen of three FVWs and its influence on the blood flow results was analysed.

The Wilcoxon Matched-pairs Signed-ranks test and the Mann-Whitney U-Wilcoxon Rank Sum W test were used for statistical analysis.

\section{RESULTS}

Twelve pregnancies were uneventful. Four pregnancies resulted in a spontaneous abortion within 1-8 weeks following the CVS procedure. In the remaining case the pregnancy was terminated as a male fetus was diagnosed after chromosome analysis in a patient carrying the fragile $\mathrm{X}$ chromosome.

Doppler waveforms could be obtained from the left uterine artery in all cases. In one patient the signals of the right uterine artery showed extensive aliasing during the two investigations after CVS. The very high peak systolic values were more than twice the pulse repetition frequency of the pulsed doppler thus preventing a proper analysis of the FVW. There were also extremely high end-diastolic velocities which indicate a low peripheral vascular resistance. This patient aborted within one week of the procedure. The overall success rate in obtaining good doppler signals at this early gestation was $98 \%$.

Mean PI ( \pm 1 SD) and mean maternal heart rate $( \pm 1 \mathrm{SD})$ relative to the CVS procedure are presented in Table 1. There was no statistically significant difference in mean PI between the left and right uterine artery for all three measuring points. There was also no statistically significant change in mean PI from each of the uterine arteries separately and from both arteries together relative to the CVS procedure. There was no statistically significant change in maternal heart rate. No correlation could be established between the maternal heart rate and PI.

Table 2 lists the individual results for each pregnancy which ended in fetal loss. PI values in these cases were nearly all situated within the normal PI range ( \pm 1 SD) established from uncomplicated pregnancies.

\section{DISCUSSION}

In normal pregnancy no significant difference in mean PI between the left and right uterine artery could be established both prior and following CVS. Whereas Deutinger et al. (1989) observed a significant difference in pulsatility (A/B ratio) between both uterine arteries in individual women, they also did not find a difference when the mean of either the left or the right measurements was considered. Both this observation and the problem regarding the clear delineation of the position of the placenta in first tri-

Table 1. Mean ( \pm 1 SD) Pulsatility Index (PI) in the right uterine artery, left uterine artery and combined left and right uterine artery relative to transcervical chorionic villus sampling (CVS) in normal pregnancies.

\begin{tabular}{lccc}
\hline & $\begin{array}{c}10 \mathrm{~min} \\
\text { before CVS }\end{array}$ & $\begin{array}{c}10 \mathrm{~min} \text { after } \\
\text { CVS }\end{array}$ & $\begin{array}{c}60 \text { min after } \\
\text { CVS }\end{array}$ \\
\cline { 2 - 4 } & mean (1 SD) & mean (1 SD) & mean (1 SD) \\
\hline $\begin{array}{c}\text { Right uterine } \\
\text { artery PI }\end{array}$ & $2.0 \quad(.82)$ & $1.94(.67)$ & $1.84(.73)$ \\
$\begin{array}{c}\text { Left uterine } \\
\text { artery PI }\end{array}$ & $2.19(.73)$ & $2.2 \quad(.91)$ & $2.29(.78)$ \\
$\begin{array}{c}\text { Right and } \\
\text { left uterine } \\
\text { artery PI }\end{array}$ & $2.08(.64)$ & $2.06(.68)$ & $2.06(.55)$ \\
$\begin{array}{c}\text { Maternal } \\
\text { heart rate } \\
\text { (bpm) }\end{array}$ & $85.1 \quad(13.5)$ & $72.7(10.4)$ & $76.2 \quad(7.0)$ \\
\hline
\end{tabular}


Table 2. Pulsatility Index (PI) values in the right and left uterine artery and maternal heartrate (bpm) relative to transcervical chorionic villus sampling (CVS) in five complicated pregnancies.

\begin{tabular}{|c|c|c|c|c|c|c|c|c|c|}
\hline \multirow[b]{2}{*}{ Patients } & \multicolumn{3}{|c|}{ Right uterine artery PI } & \multicolumn{3}{|c|}{ Left uterine artery PI } & \multicolumn{3}{|c|}{ Maternal heartrate/bpm } \\
\hline & $\begin{array}{l}10 \mathrm{~min} \\
\text { before } \\
\text { CVS }\end{array}$ & $\begin{array}{l}10 \min \\
\text { after } \\
\text { CVS }\end{array}$ & $\begin{array}{l}60 \mathrm{~min} \\
\text { after } \\
\text { CVS }\end{array}$ & $\begin{array}{l}10 \text { min } \\
\text { before } \\
\text { CVS }\end{array}$ & $\begin{array}{l}10 \min \\
\text { after } \\
\text { CVS }\end{array}$ & $\begin{array}{l}60 \text { min } \\
\text { after } \\
\text { CVS }\end{array}$ & $\begin{array}{c}10 \mathrm{~min} \\
\text { before } \\
\text { CVS }\end{array}$ & $\begin{array}{l}10 \mathrm{~min} \\
\text { after } \\
\text { CVS }\end{array}$ & $\begin{array}{l}60 \mathrm{~min} \\
\text { after } \\
\text { CVS }\end{array}$ \\
\hline $1^{+}$ & 0.97 & & & 1.94 & 1.75 & 1.65 & 52 & 51 & 60 \\
\hline $2^{\dagger}$ & 1.68 & 1.68 & 1.24 & 2.58 & 2.61 & 1.71 & 75 & 73 & 65 \\
\hline $3^{\dagger}$ & 1.74 & 1.60 & 1.70 & 1.60 & 2.54 & 2.36 & 63 & 63 & 66 \\
\hline $4^{\dagger}$ & 2.18 & 1.66 & 2.33 & 2.02 & 2.19 & 2.32 & 83 & 70 & 86 \\
\hline $5^{\ddagger}$ & .89 & 2.04 & 3.29 & 1.89 & 1.95 & 2.65 & 102 & 87 & 92 \\
\hline
\end{tabular}

${ }^{\dagger}$ Patients who experienced a spontaneous abortion 1, 4, 5, and 8 weeks after the CVS procedure.

₹ The pregnancy was terminated as a male fetus was diagnosed in a patient carrying the fragile $\mathrm{X}$ chromosome.

mester pregnancies, led to the decision to combine left and right uterine PI data, thus providing information on total uterine perfusion. A similar suggestion was made by Stabile et al. (1988) on the basis of a close correlation between the pulsatility (Resistance Index) in the left and right uterine artery flow velocity waveforms in early gestation.

No change was observed in the normal PI values from the right and left uterine artery separately and from both arteries together relative to the CVS procedure. This suggests that this intrauterine procedure does not alter uteroplacental blood flow in uncomplicated first trimester pregnancies.

Previous Doppler studies in fetal vessels have demonstrated an inverse relationship between fetal heart rate and PI (Mires et al. 1987; Van den Wijngaard et al. 1988; Hoskins et al. 1989). In the present study no such relationship could be documented for maternal heart rate and PI from the uterine artery, which may have been determined by the relatively narrow heart rate range. Khong and Pearce (1987) observed immature development of trophoblast invasion in the spiral arteries causing inadequate vascular adaptive changes in patients with recurrent firsttrimester spontaneous abortion. This suggests that uteroplacental vasculature could not develop into a low resistance system needed for optimal oxygen and nutrient supply to the developing fetus. The flow velocity waveforms of the uterine artery would then show a high resistance pattern. The risk of fetal loss following the CVS procedure is significantly higher at advanced maternal age (Jahoda et al. 1987). Increased spontaneous fetal loss at advanced maternal age has been attributed to biological aging of the uterine arteries (Stein 1985). In the present study, however, both before and after CVS procedure, PI values from the aborted fetuses were not essentially different from those obtained in normal pregnancy.
Three out of four pregnancies which ended in spontaneous fetal loss were from mothers of advanced maternal age. This suggest that also here uteroplacental blood flow was not affected by the CVS procedure and the subsequent high fetal loss rate was not the result of pathological alterations in uteroplacental vasculature.

In conclusion, no significant changes in uteroplacental vascular resistance were observed relative to the CVS procedure both in uncomplicated pregnancies and in pregnancies ending in second trimester fetal loss. Uteroplacental vascular resistance appeared not to be essentially different between the two pregnancy groups.

\section{REFERENCES}

American Institute of Ultrasound in Medicine. Statement on mammalian in vivo ultrasonic biological effects. J. Clin. Ultrasound $5: 2-3 ; 1977$.

Boogert, A.; Mantingh, A.; Visser, G. H. A. The immediate effects of chorionic villus sampling on fetal movements. Am. J. Obstet. Gynecol. 157:137-139; 1987.

Brambati, B.; Oldrini, A.; Ferrazzi, E.; Lanzani, A. Chorionic villus sampling: Analysis of the obstetric experience of 1000 cases. Prenatal Diagnosis 7:157-169; 1987.

Campbell, S.; Diaz-Recasens, J.; Griffin, D. R.; Cohen-Overbeek, T. E.; Pearce, J. M.; Wilson, K.; Teague, M. J. New Doppler technique for assessing uteroplacental bloodflow. Lancet i:675-677; 1983 .

Deutinger, J.; Rudelstorfer, R.; Bernaschek, G. Vaginosonographic velocimetry of both main uterine arteries by visual vessel recognition and pulsed Doppler method during pregnancy. Am. J. Obstet. Gynecol. 159:1072-1076; 1988.

Gosling, R. G.; King, D. H. Ultrasonic angiology. In: Marcus, A. W.; Adamson, L., eds. Arteries and veins. New York: Churchill Livingstone; 1975:61-98.

Hoskins, P. R.; Johnstone, F. D.; Chambers, S. E.; Hadded, N. G.; White, G.; McDicken, W. N. Heart rate variation of umbilical artery Doppler waveforms. Ultrasound Med. Biol. 15:101-107; 1989.

Jahoda, M. G. J.; Vosters, R. P. L.; Sachs, E. S.; Galjaard, H. Safety of chorionic villus sampling. Lancet ii:941-42; 1985.

Jahoda, M. G. J.; Pijpers, L.; Vosters, R. P. L.; Wladimiroff, J. W.; 
Reuss, A.; Sachs, E. S. Role of maternal age in assessment of risk of abortion after prenatal diagnosis during first trimester. Br. Med. J. 295:1237; 1987.

Khong, T. Y.; Pearce, J. M. Development and investigation of the placenta and its blood supply. In: Lavery, J. P., ed. The human placenta. Rockville, MD: Aspen Publications; 1987:25-45.

Mires, G.; Dempster, J.; Patel, N. B.; Crawford, J. W. The effect of heart rate on umbilical flow velocity waveform. Br. J. Obstet. Gynaecol. 94:665-669; 1987.

Sachs, E. S.; Jahoda, M. G. J.; Kleijer, W. J.; Pijpers, L.; Galjaard, H. Impact of first trimester chromosome, DNA and Metabolic studies on pregnancies at high genetic risk. Am. J. Med. Genet. 29:293-303; 1988.

Stabile, I.; Bilardo, C.; Panella, M.; Campbell, S.; Grudzinskas, G. Doppler assessed uterine bloodflow in the first trimester of pregnancy. Trophoblast Res. 3:301-308; 1988.
Stein, Z. A. A woman's age: childbearing and childrearing. Am. J. Epidemiology 121:327-342; 1985.

van den Wijngaard, J. A. G. W.; van Eyck, J.; Wladimiroff, J. W. The relationship between fetal heart rate and Doppler blood flow velocity waveform. Ultrasound Med. Biol. 14:593-599; 1988.

Ward, R. H. T.; Grudzinskas, J. G.; Bolton, A. E.; Modell, B.; Kanakpongsukdi, S.; Petrou, M.; Chard, T. Fetoplacental products as a prognostic guide following chorionic villus sampling. In: Fraccaro, M.; Simoni, G.; Brambati, B., eds. First trimester fetal diagnosis. Berlin: Springer Verlag; 1985:74-77.

Warren, R. C.; Butler, J.; Morsman, J. M.; McKenzie, C.; Rodeck, C. H. Does chorionic villus sampling cause fetomaternal haemorrhage? Lancet i:691; 1985.

Williams, J.; Medearis, A. L.; Bear, M. B.; Kaback, M. M. Chorionic villus sampling is associated with normal fetal growth. Am. J. Obstet. Gynecol. 157:708-712; 1987. 